LHCb Vertex Locator commissioning and results from the first LHC beam reconstructed tracks

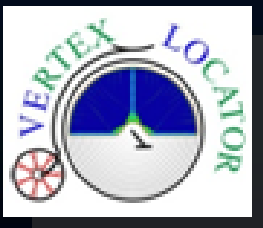
Silvia Borghi on behalf of the LHCb VELO group

LHCD

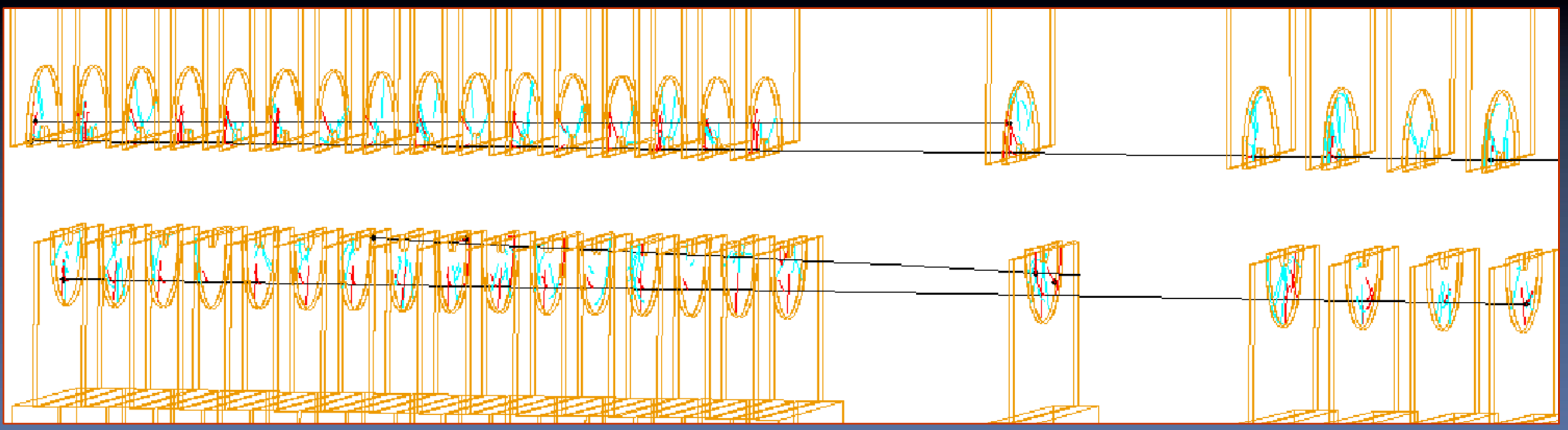




\section{The LHCb experiment}

* LHCb is an experiment dedicated to heavy flavour physics at the LHC.

* Its primary goal to look for indirect evidence of new physics in CP violation and rare decays of beauty and charm hadrons.

* Forward spectrometer: $1.9<\eta<4.9$ [b $\bar{b}$ - pairs produced correlated in space]

* Luminosity: $2 \cdot 10^{32} \mathrm{~cm}^{-2} \mathrm{~s}^{-1}\left[10^{12} \mathrm{~b} \bar{b}\right.$-pairs per year]

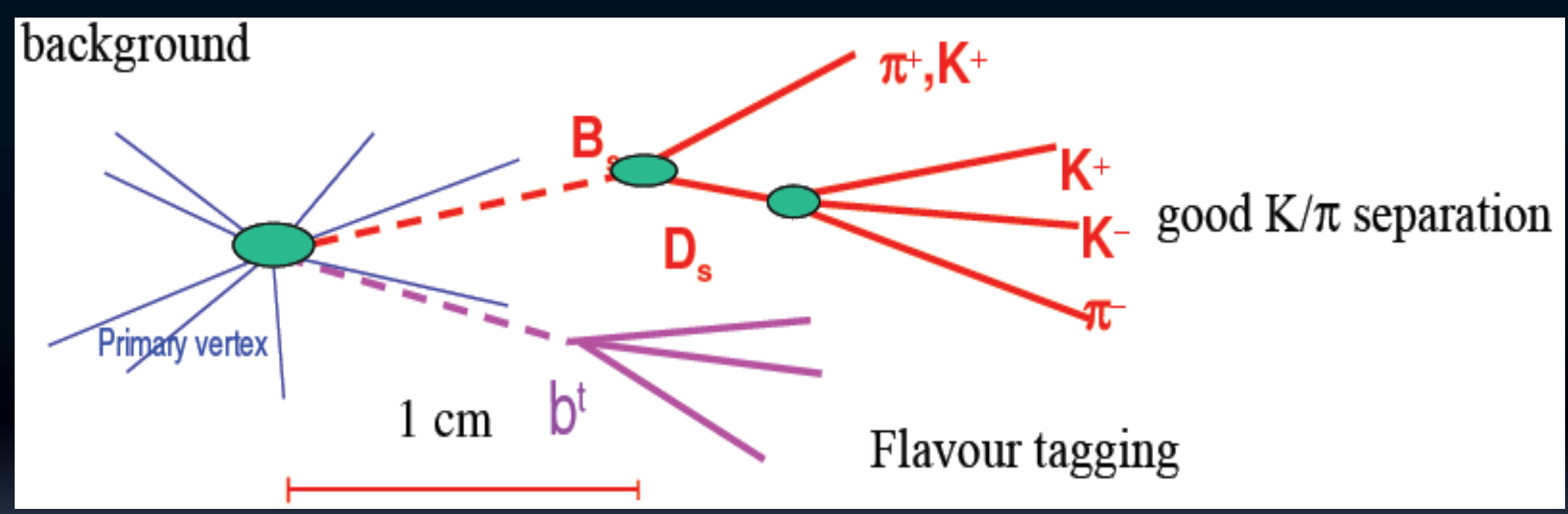

Main detector requirements

Reconstruction in harsh radiation environment

- Selective trigger system [bБ-production cross-section small]

Good vertex resolution [proper time]

- Good particle identification [K/ $/ \pi$ separation] 


\section{VELO: VErtexLOcator}

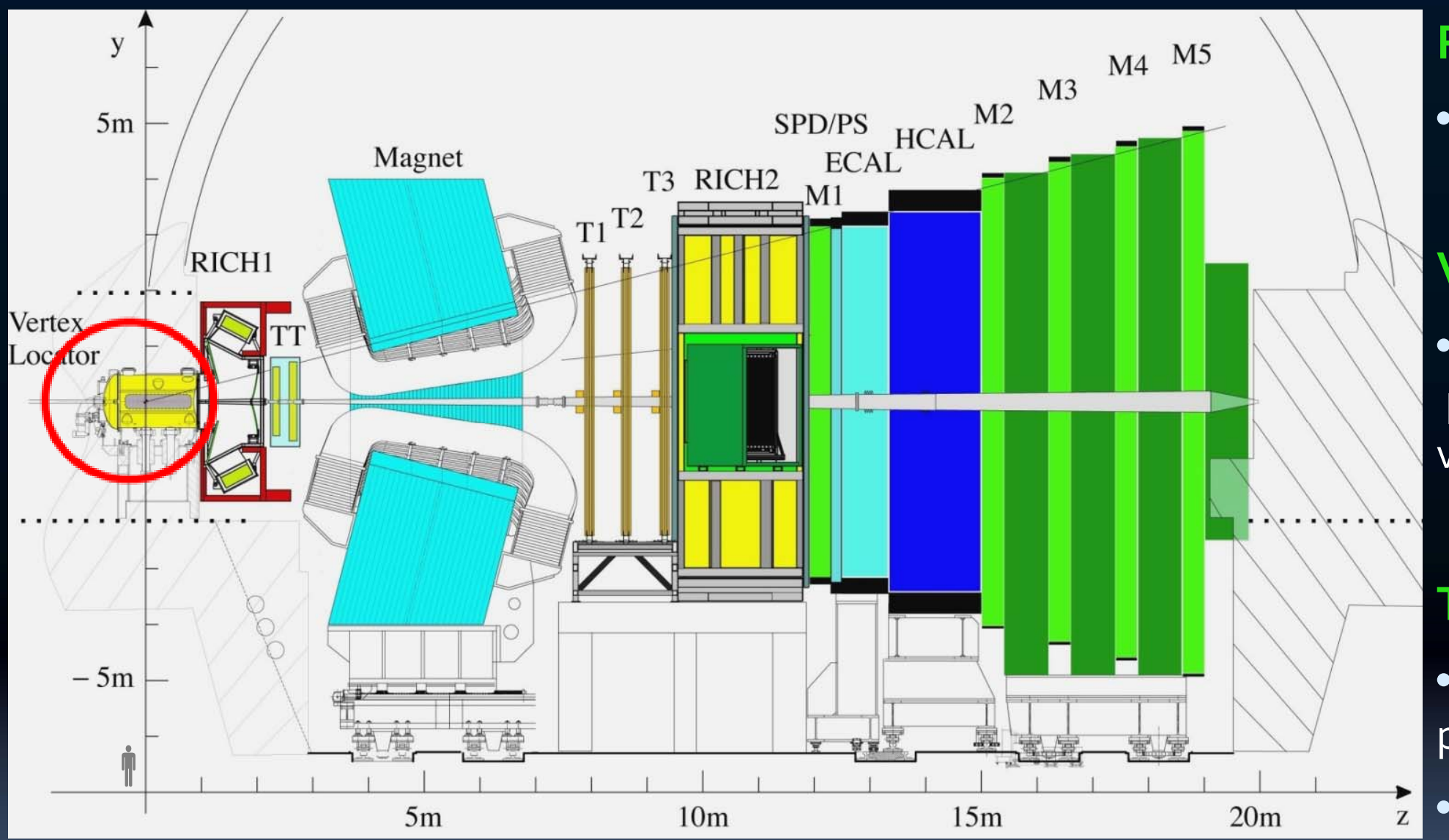

Reconstruction

-Precise tracking

Vertexing

- Need to separate primary and secondary vertices

\section{Trigger}

- Fast reconstruction primary vertices -B-decay selection

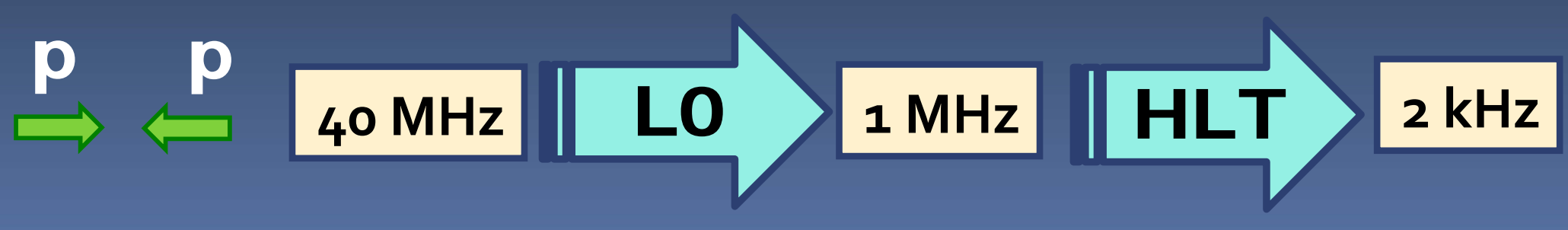




\section{Expected Tracking Performance}

\section{LHCb acceptance: $1.9<\eta<4.9$}

For typical B decay modes:

- primary vertex resolution:

$$
x, y: \sim 10 \mu \mathrm{m}, z: \sim 60 \mu \mathrm{m}
$$

- proper time res.: $\sim 40$ fs

- B mass res.: 12 - $25 \mathrm{MeV}$

- Impact parameter resolution

$13 \mu \mathrm{m}+35 \mu \mathrm{m} / \mathrm{pt}$
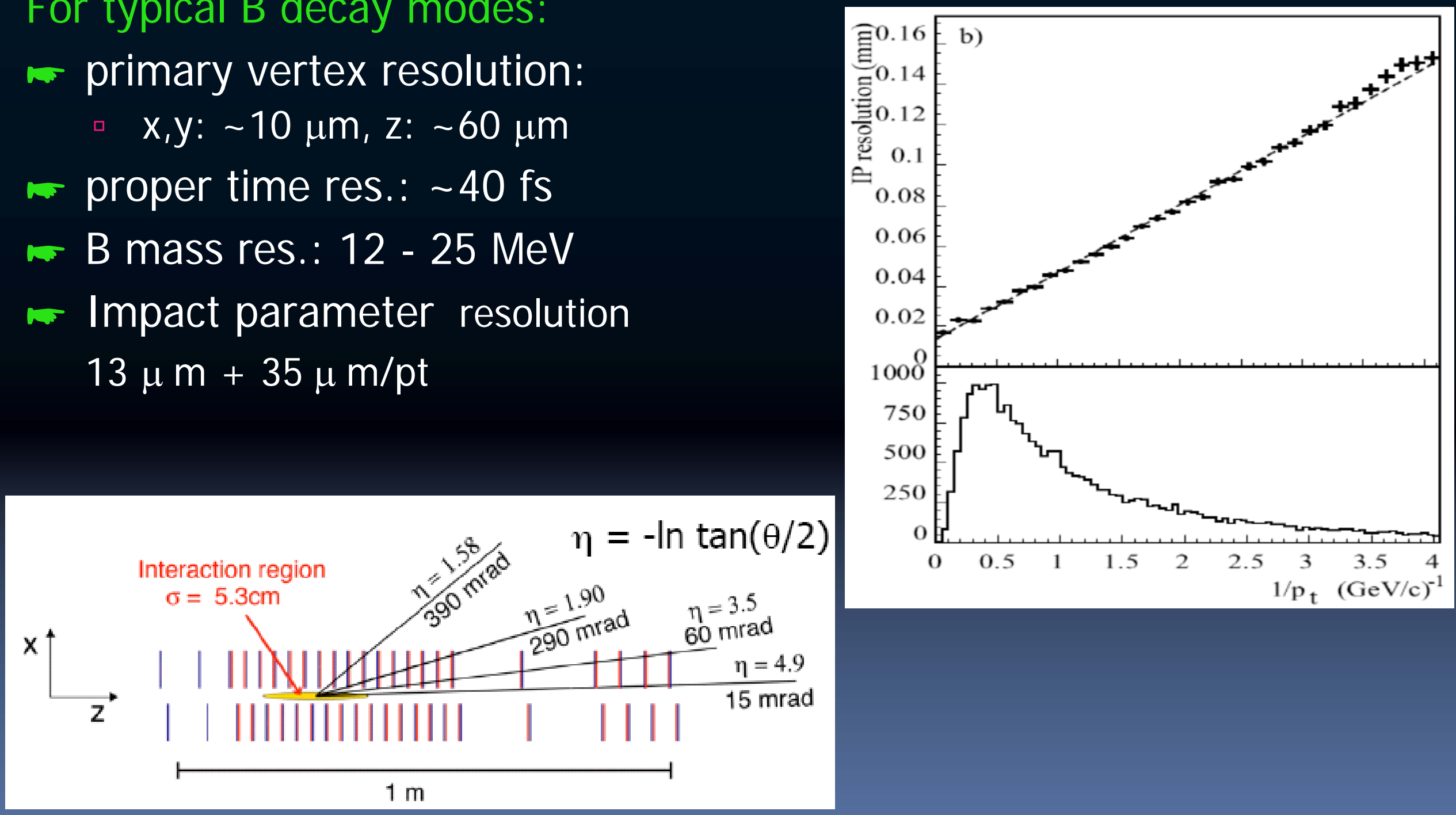


\section{VELO Layout}
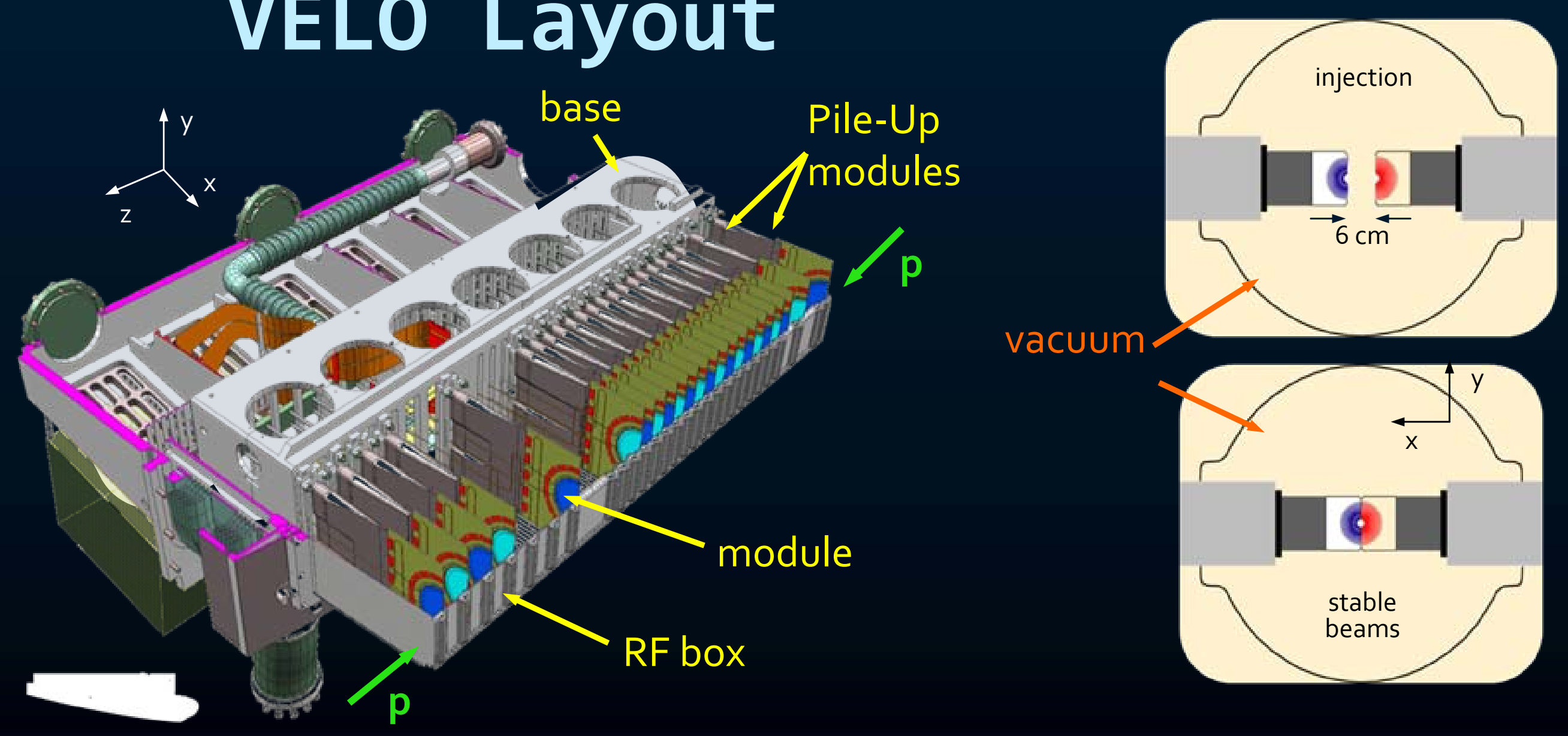

* 2 retractable detector halves:5 $\mathrm{mm}$ from beam when closed, $30 \mathrm{~mm}$ from beam during injection

* 21 stations per half with an $\mathrm{R}$ and $\phi$ sensor

\& 2 Pile-Up stations per half [trigger]

* Operates in secondary vacuum

* 300 $\mu \mathrm{m}$ foil separates detector from beam vacuum

2 phase $\mathrm{CO}_{2}$ cooling system 


\section{Sensors}

$\mathrm{n}^{+}$in $\mathrm{n}$-bulk sensors [300 $\mu \mathrm{m}$ ]

- inherently radiation tolerant

- strip isolation via p-spray

- expected radiation dose:

$-1.3 \cdot 10^{14} \mathrm{n}_{\mathrm{eq}} / \mathrm{cm}^{2} /$ year at $\mathrm{r}=0.8 \mathrm{~cm}$

$-5 \cdot 10^{12} \mathrm{n}_{\mathrm{eq}} / \mathrm{cm}^{2} /$ year at $\mathrm{r}=4.2 \mathrm{~cm}$

after 3-4 years [ $8 \mathrm{fb}^{-1}$ ]: run partially depleted
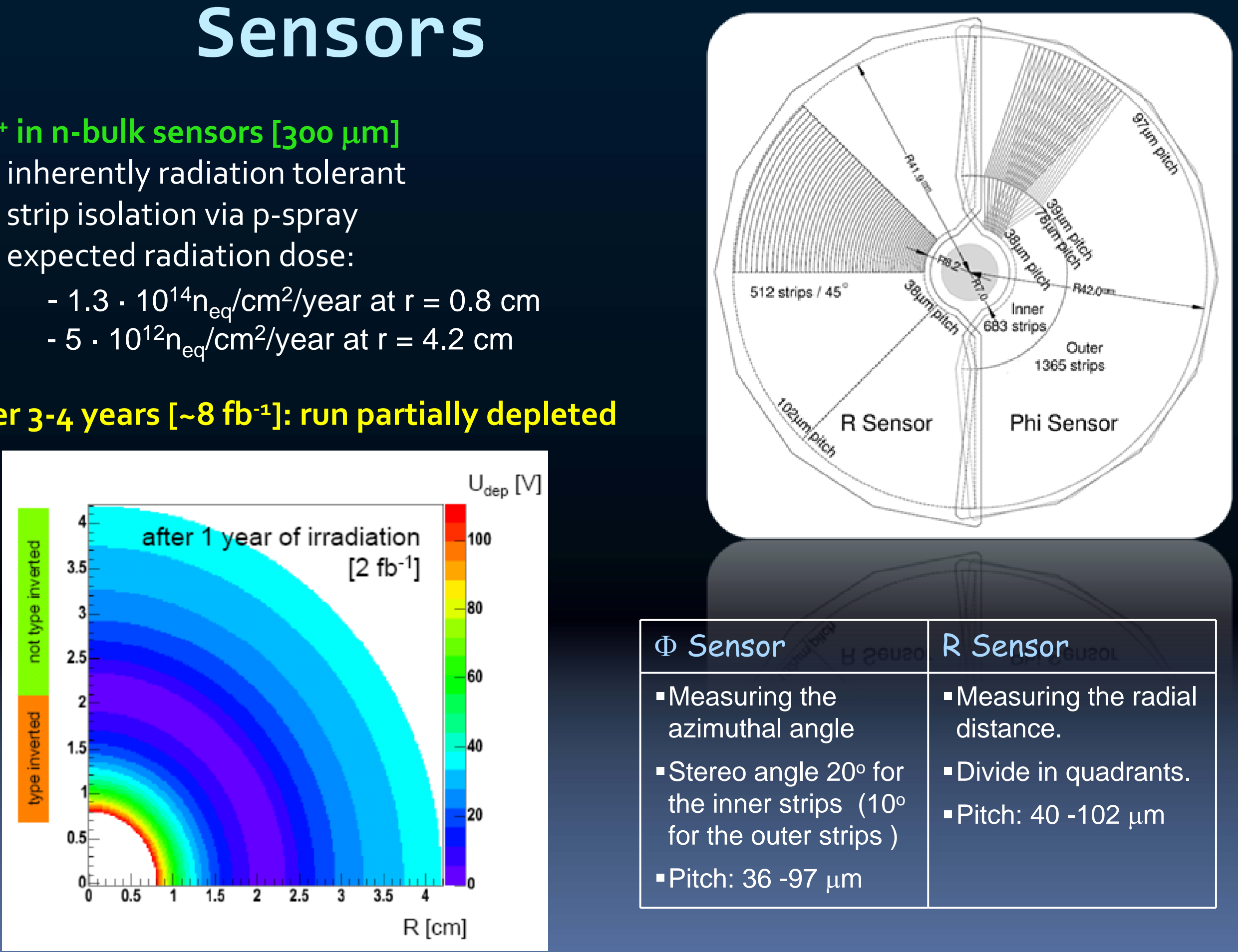

\begin{tabular}{|c|c|}
\hline$\Phi$ Sensor & R Sensor \\
\hline $\begin{array}{l}\text { - Measuring the } \\
\text { azimuthal angle }\end{array}$ & $\begin{array}{l}\text {-Measuring the radial } \\
\text { distance. }\end{array}$ \\
\hline $\begin{array}{l}\text { - Stereo angle } 20^{\circ} \text { for } \\
\text { the inner strips }\left(10^{\circ}\right. \\
\text { for the outer strips ) }\end{array}$ & $\begin{array}{l}\text { - Divide in quadrants. } \\
\text { - Pitch: } 40-102 \mu \mathrm{m}\end{array}$ \\
\hline -Pitch: 36 -97 um & \\
\hline
\end{tabular}




\section{Module}

\section{Basic functions:}

-hold the sensors in a fixed position relative to the module support.

- connect the electrical readout to the sensors

-enable cooling of the sensor.

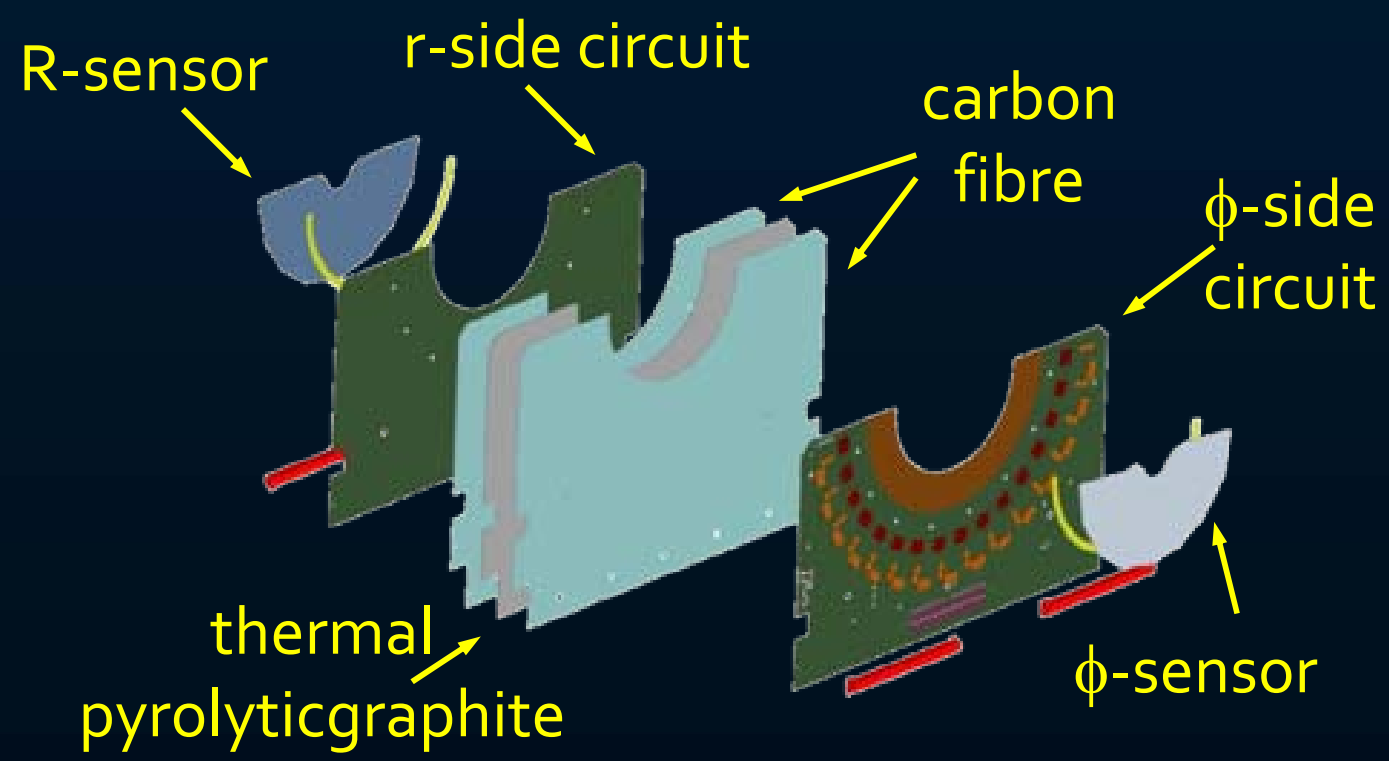

- double-sided hybrid to balance stresses due to "bi-metallic" effects

- sensor-sensor accuracy: <5

- analogue front-end read-out: $2 \times 16$ Beetle chips

- cooling: 2-phase $\mathrm{CO}_{2}$ [silicon @ - $5^{\circ} \mathrm{C}$ ]

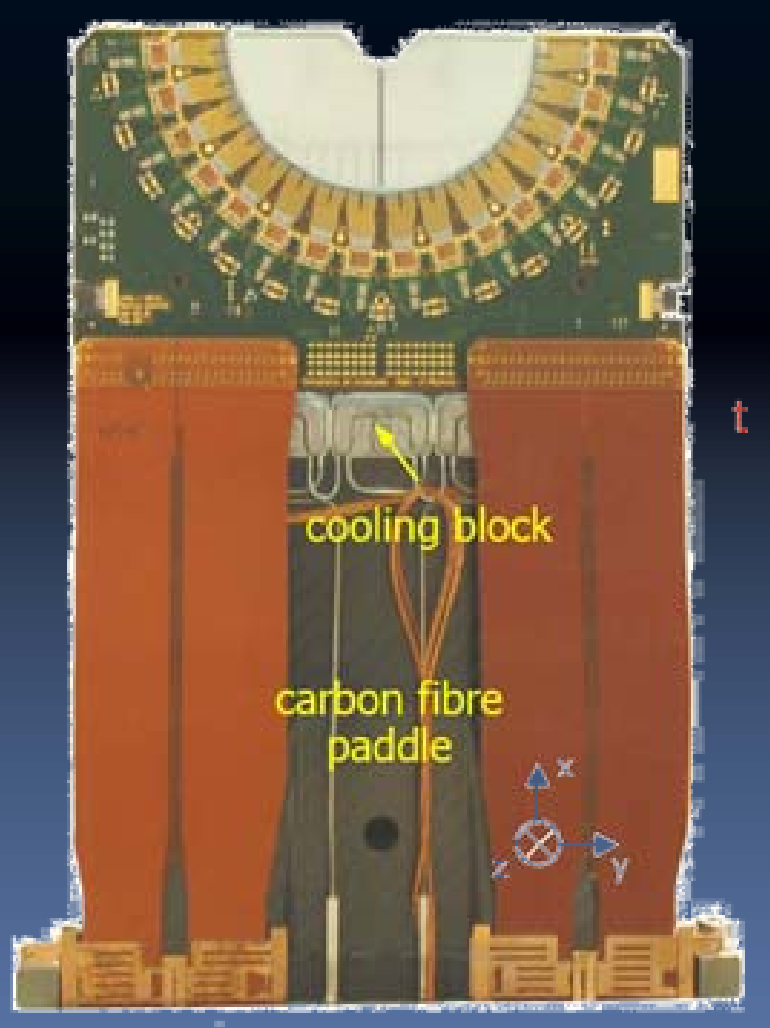




\section{Vacuum System}

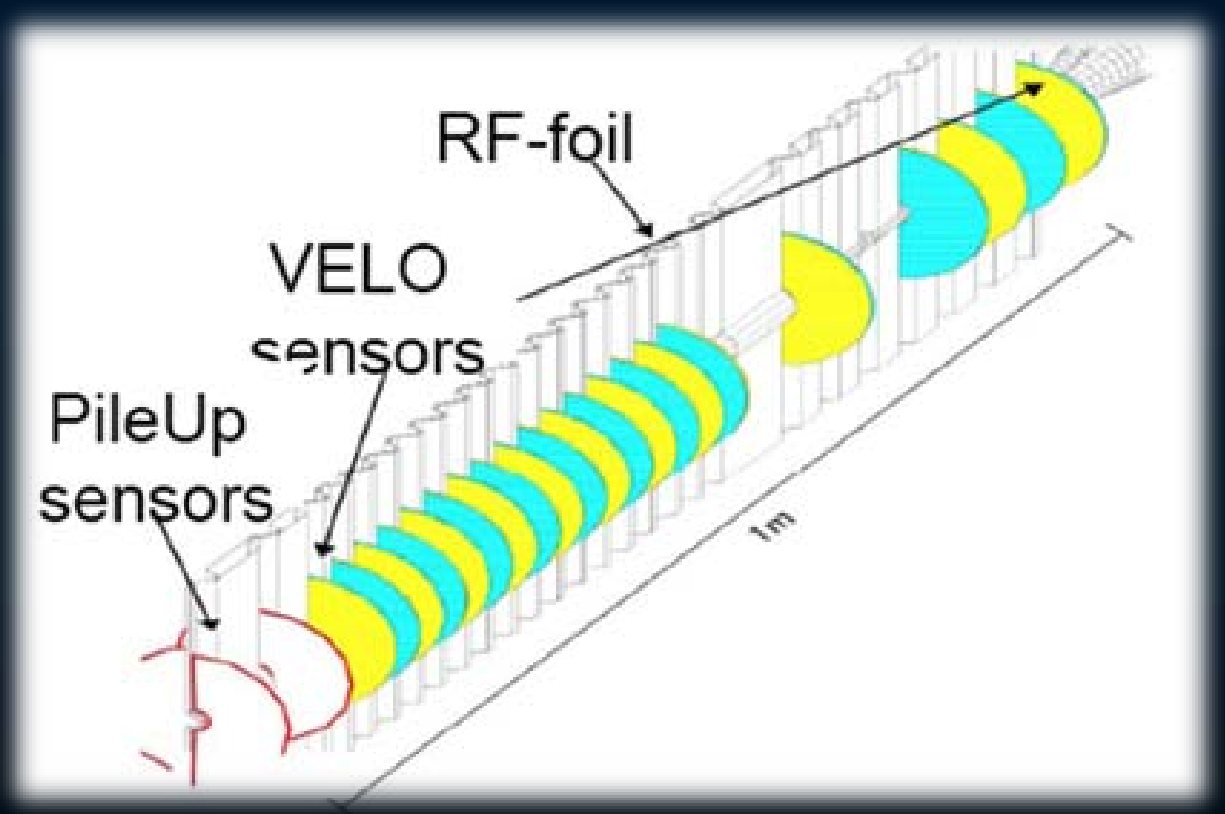

-silicon detectors operated in vacuum

RF shield of $300 \mu \mathrm{m} \mathrm{Al} \mathrm{[3 \%} \mathrm{Mg]}$

- constitutes beam-pipe in VELO region

- shape allows for overlapping sensors [alignment]
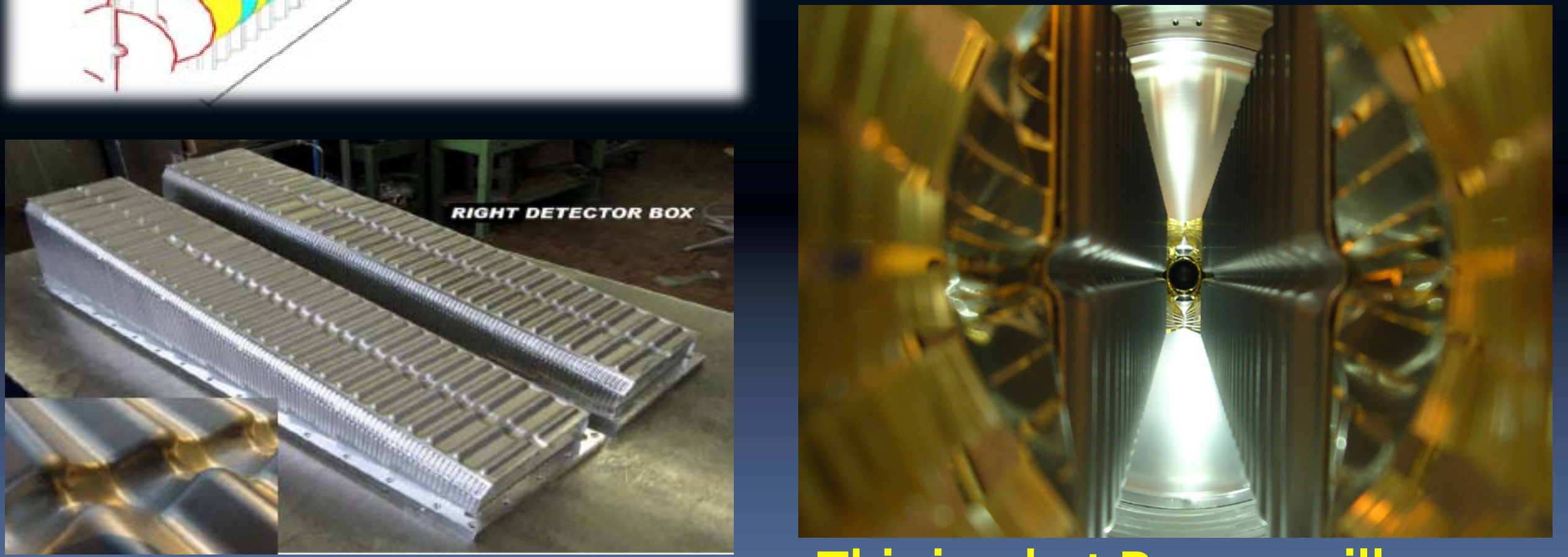

This is what Beam1 will see ... 


\section{Cooling system}

- bi-phase $\mathrm{CO}_{2}$ cooling system

Operation temperature of the sensors below $-5 \mathrm{C}$

Detector temperature (evaporator) is controlled by the pressure in the accumulator

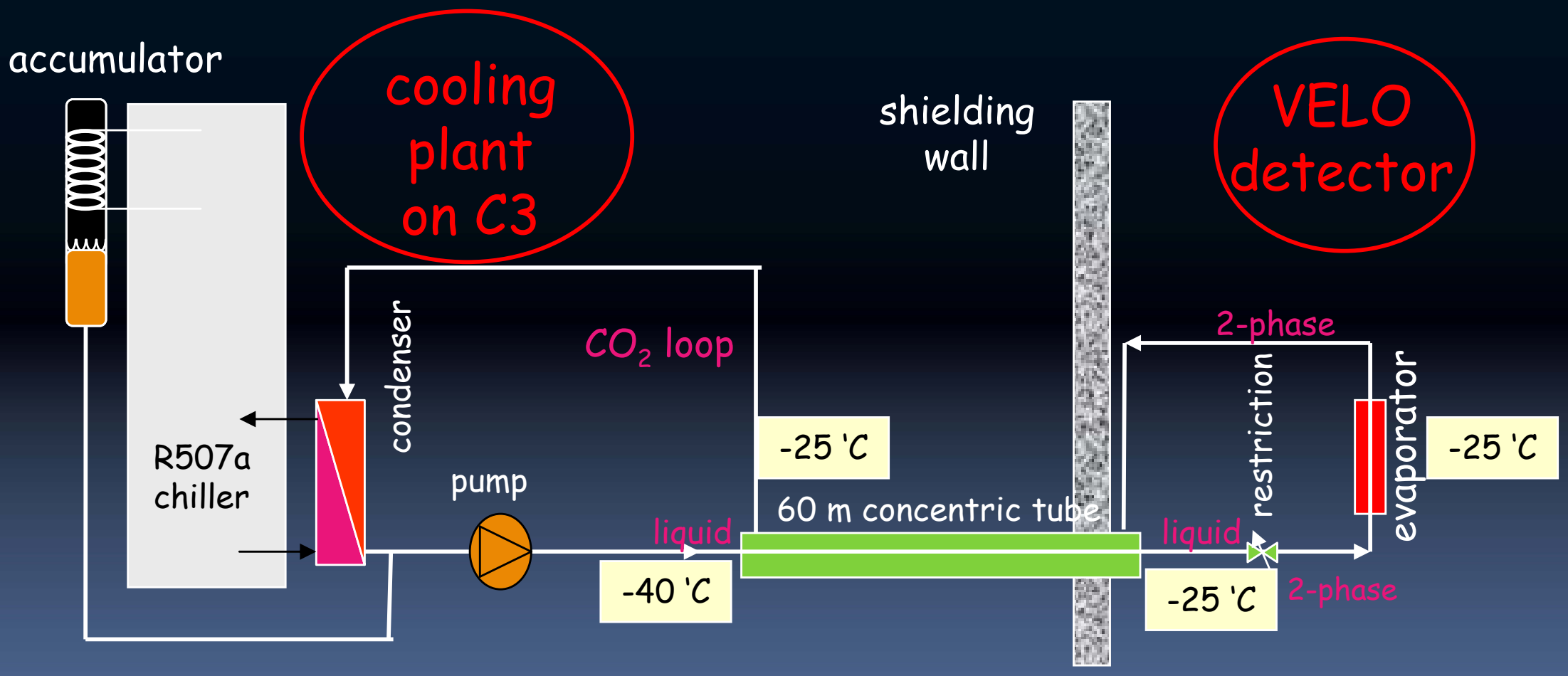




\section{Electronics overview}

\section{TELL1 board}

- Analog input from 64 links

r 1obit ADC @ 40 MHz

- FPGA for preprocessing (pedestal subtraction, crosstalk, common mode suppression, clustering)

- Maximum output rate is $1.1 \mathrm{MHz}$
Readout chain for one side of one module

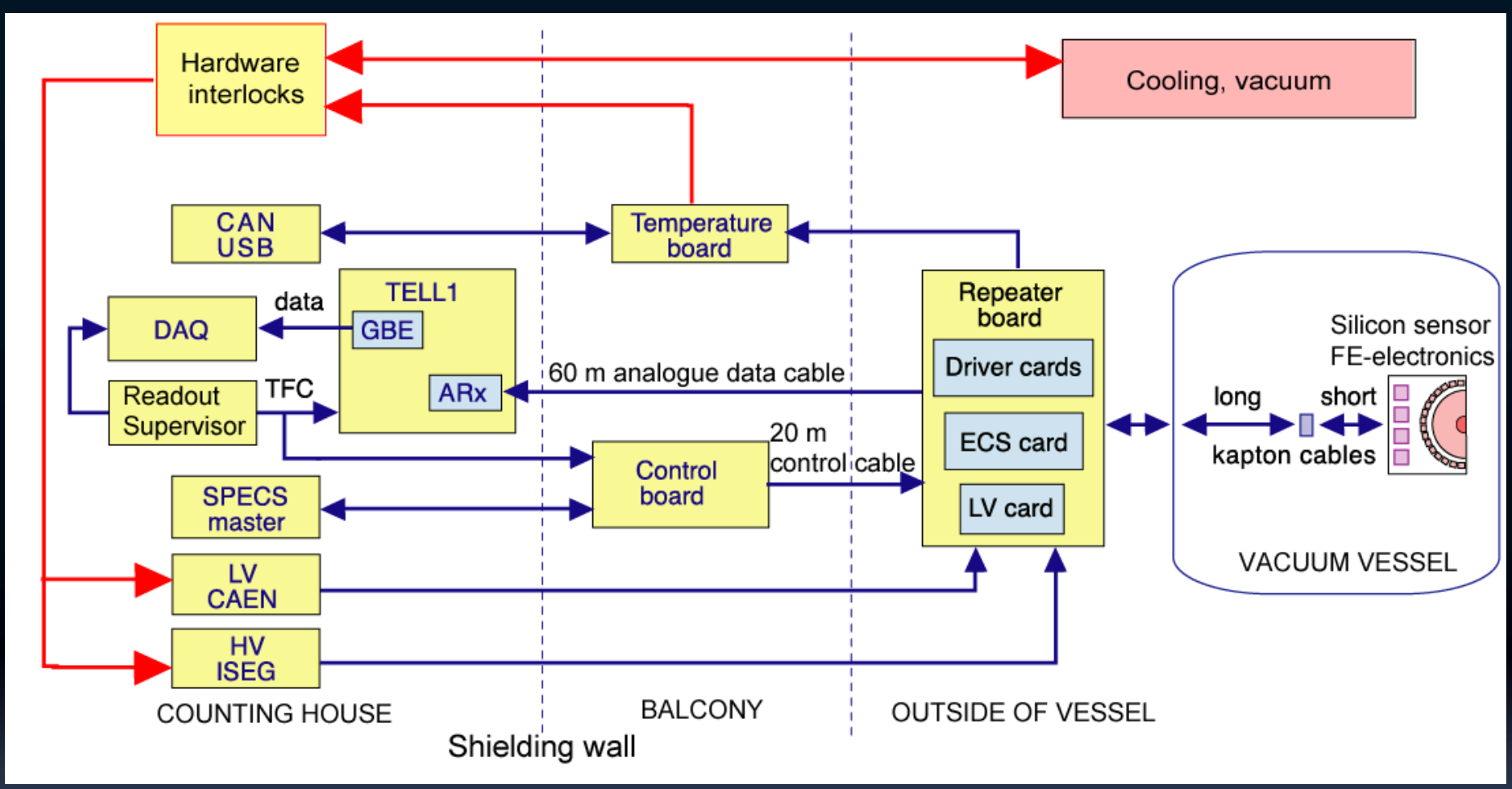

All components were installed. Each system commissioned stand-alone. 


\section{Production, testing and installation}

\section{Vacuum Tank}

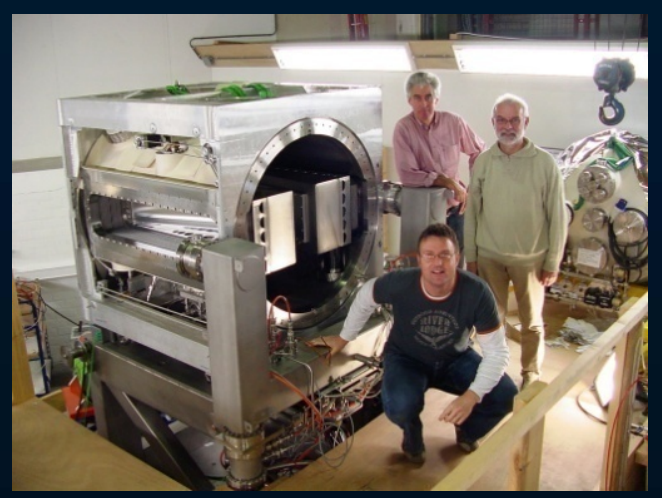

Electronics

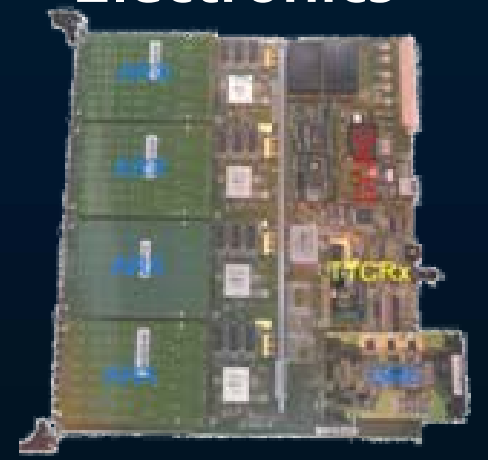

$\mathrm{CO}_{2}$ cooling
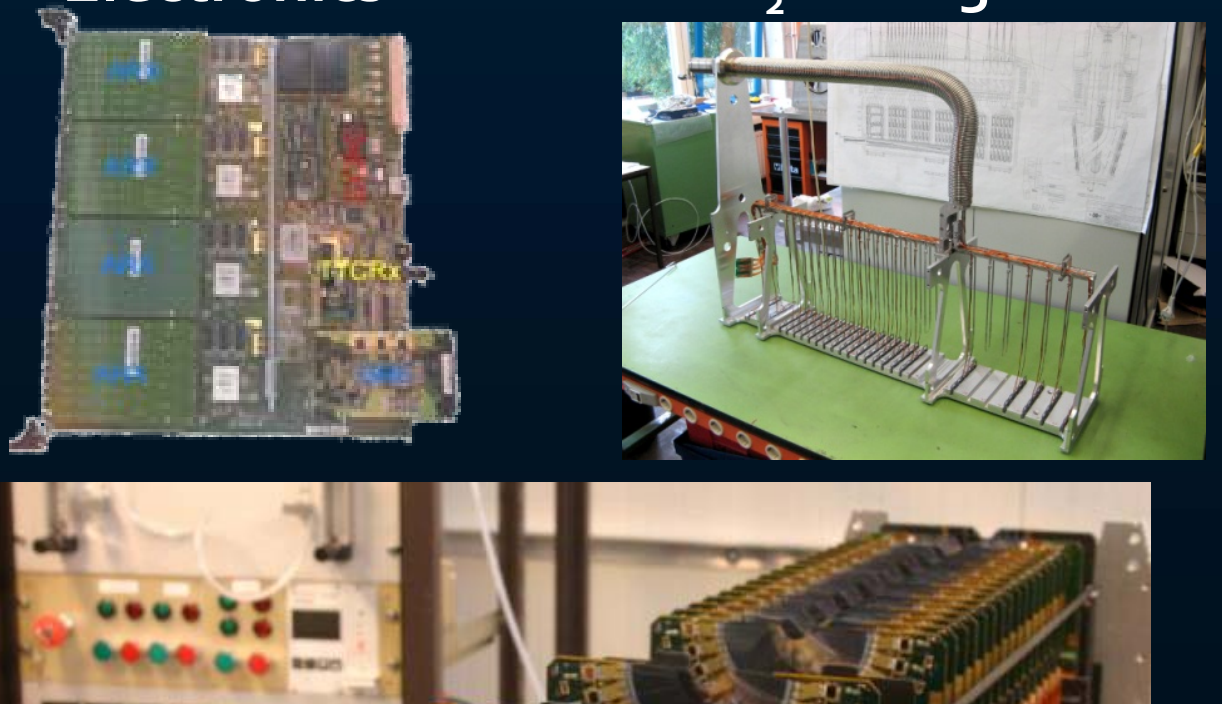

Installation of one half

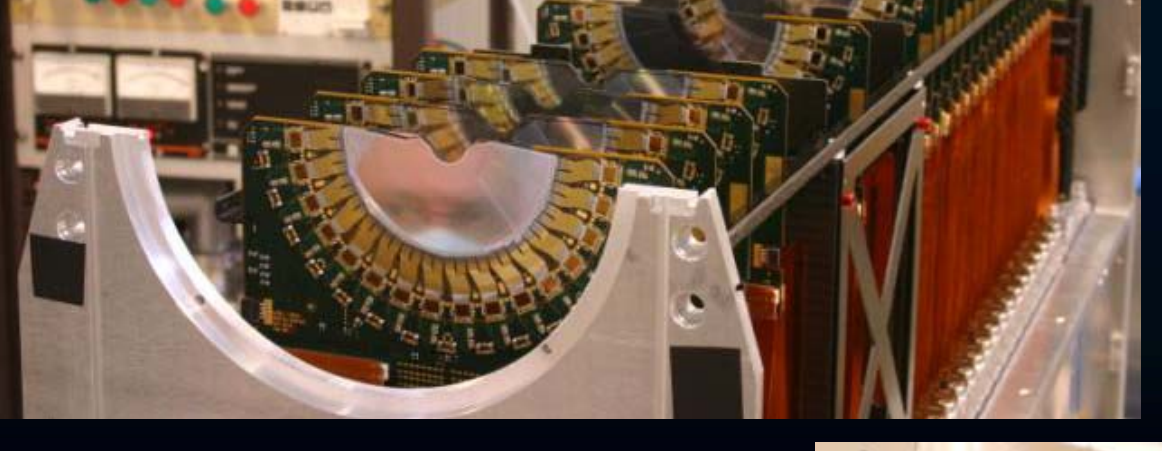

Module production
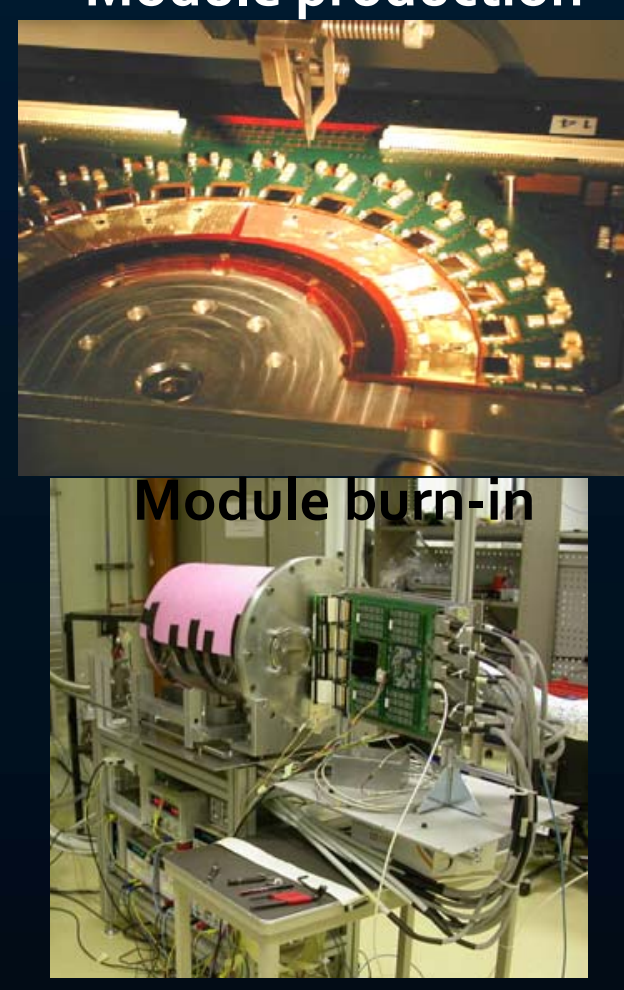

Lowering into the LCb cavern

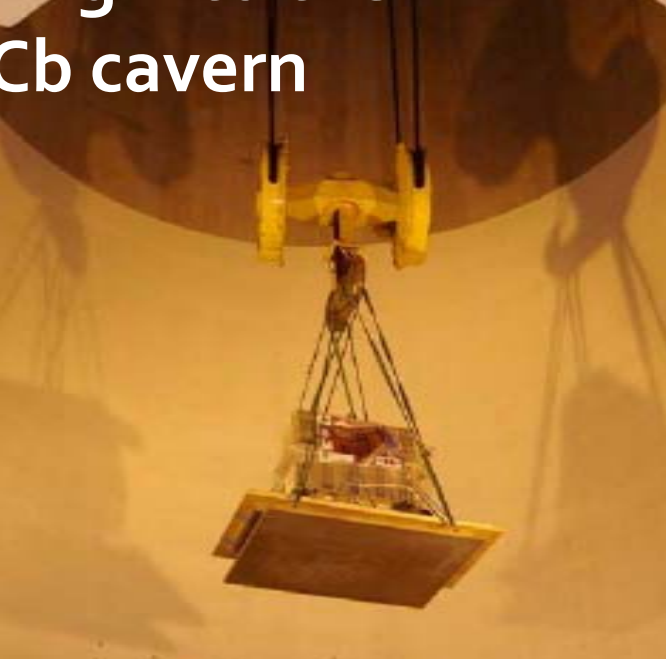

October 2007

TIPPog - 12 March 2009

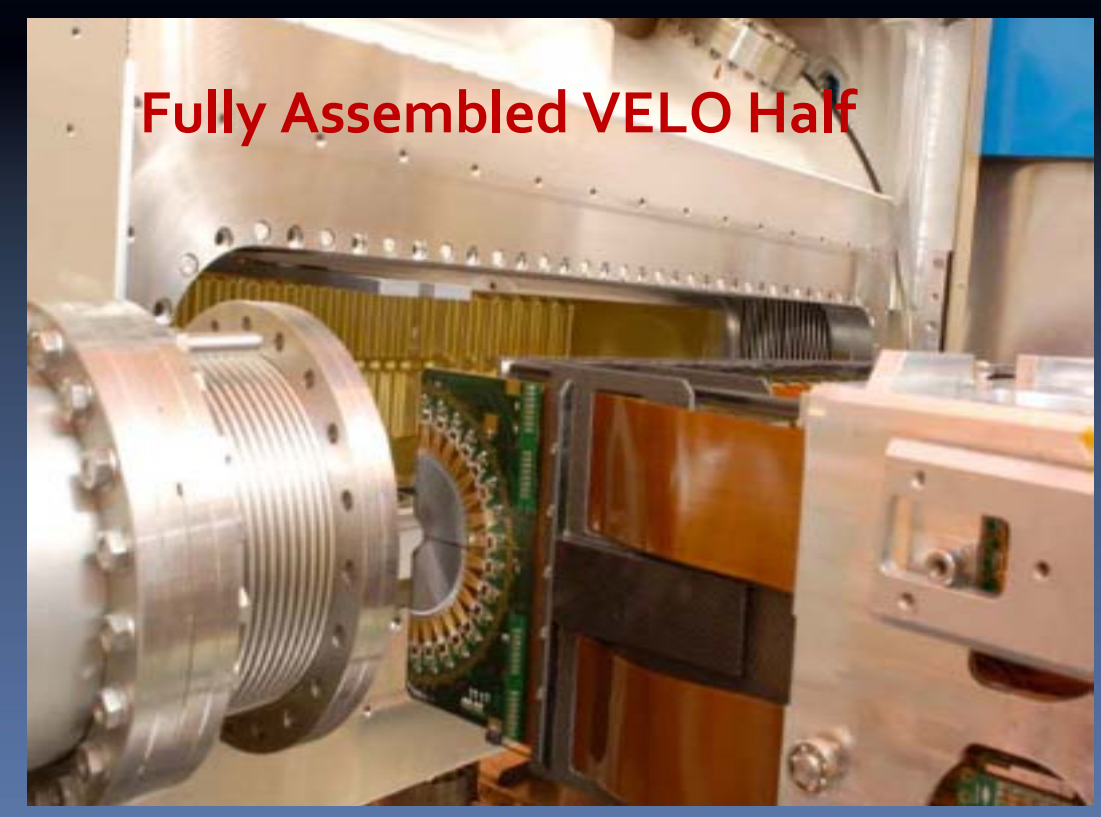




\section{Commissioning the VELO}

$\checkmark$ Single module operation under Neon atmosphere - $\mathbf{1 8}^{\text {th }}$ March 2008.

$\checkmark \quad$ Noise level compared with previous data taken in assembly

$\checkmark$ Operation of 15 modules on $15^{\text {th }}$ May 2008

$\checkmark$ Single module test of $2^{\text {nd }}$ half from $2^{\text {nd }}$ June 2008.

$\checkmark \quad$ Full half powered for first time June $10^{\text {th }} 2008$.

$\checkmark$ First operation in vacuum $\mathbf{- 1 8 ^ { \text { th } }}$ June 2008

System @ full power

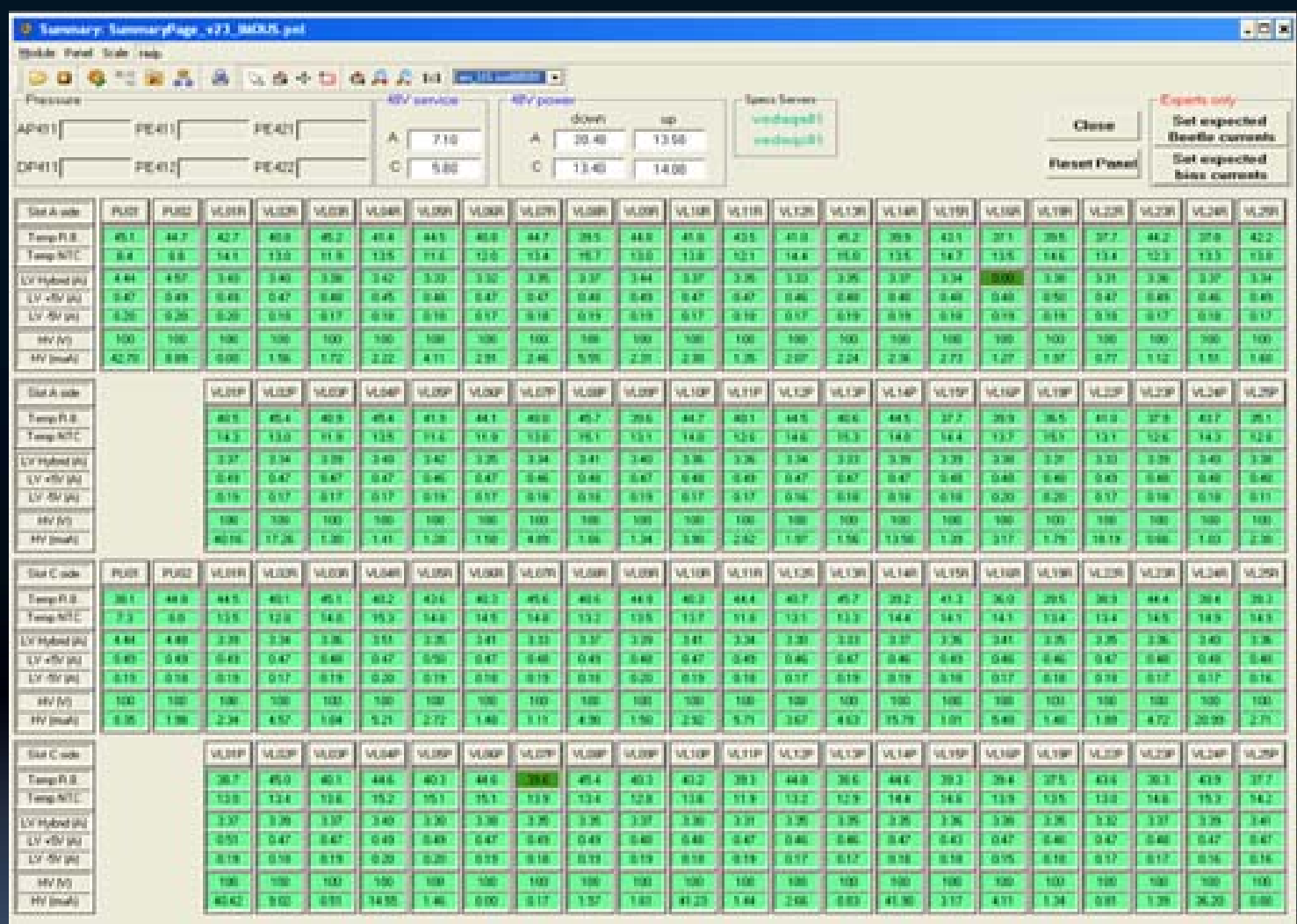

$\checkmark$ Full detector operated under vacuum.

$\checkmark$ Operated cooling fully loaded at $-25 \mathrm{C}$

$\checkmark$ Modules@-5C 


\section{VELO under vacuum}

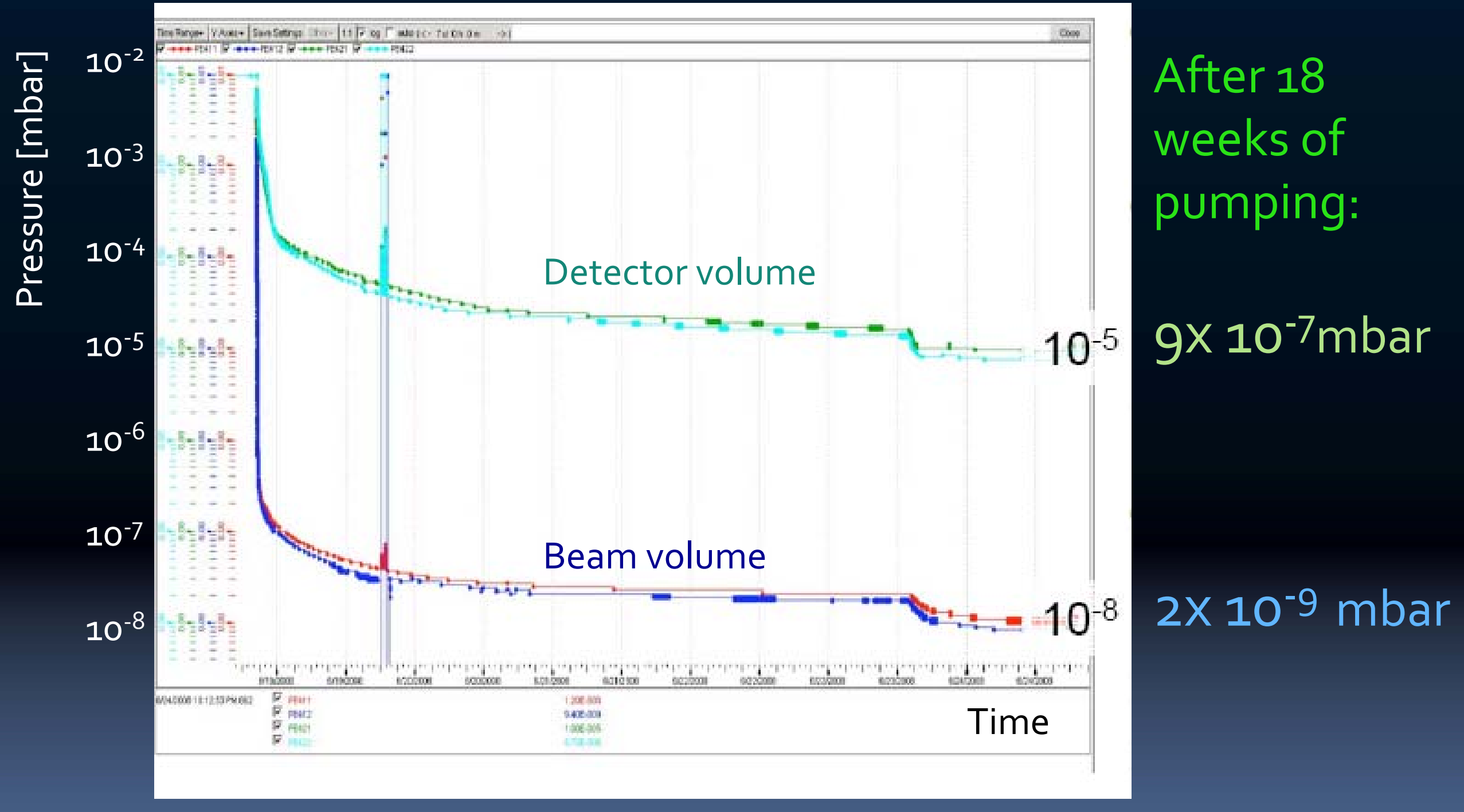

Specifications of the pressure $10^{-4} \mathrm{mbar}$ in Detector volume and $10^{-8}$ in the beam volume 


\section{LHC synchronization test}

\section{in August and September 2008}

$\square$ Beam 2 dumped on injection line beam stopper (TED)

Beam

- 1 shot each 48 seconds

- About $510^{9}$ protons per shot

TED is an absorber at the end of the injection line

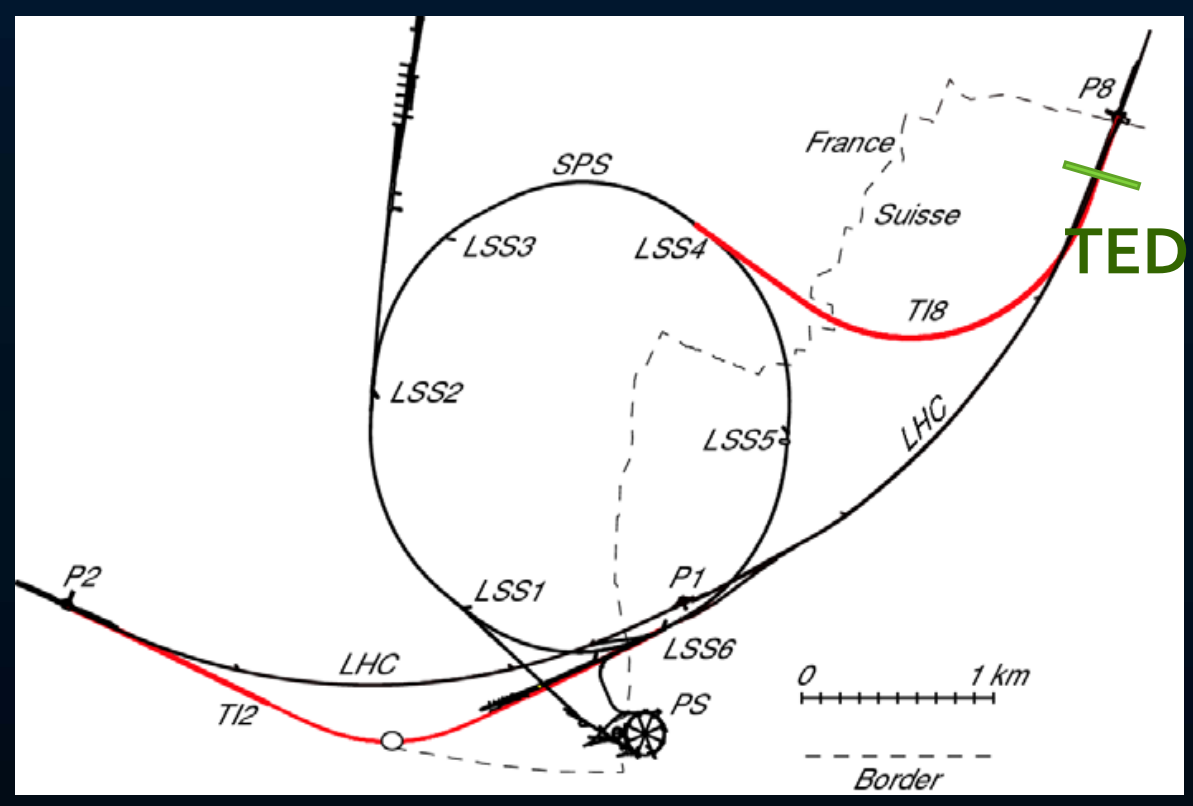

- $4 \mathrm{~m}$ tungsten, copper, aluminium, graphite rod in a $1 \mathrm{~m}$ diameter iron casing

- 340m before LHCb along beam 2

- 8 mrad horizontally and $12 \mathrm{mrad}$ vertically from $\mathrm{LHCb}$ beam axis

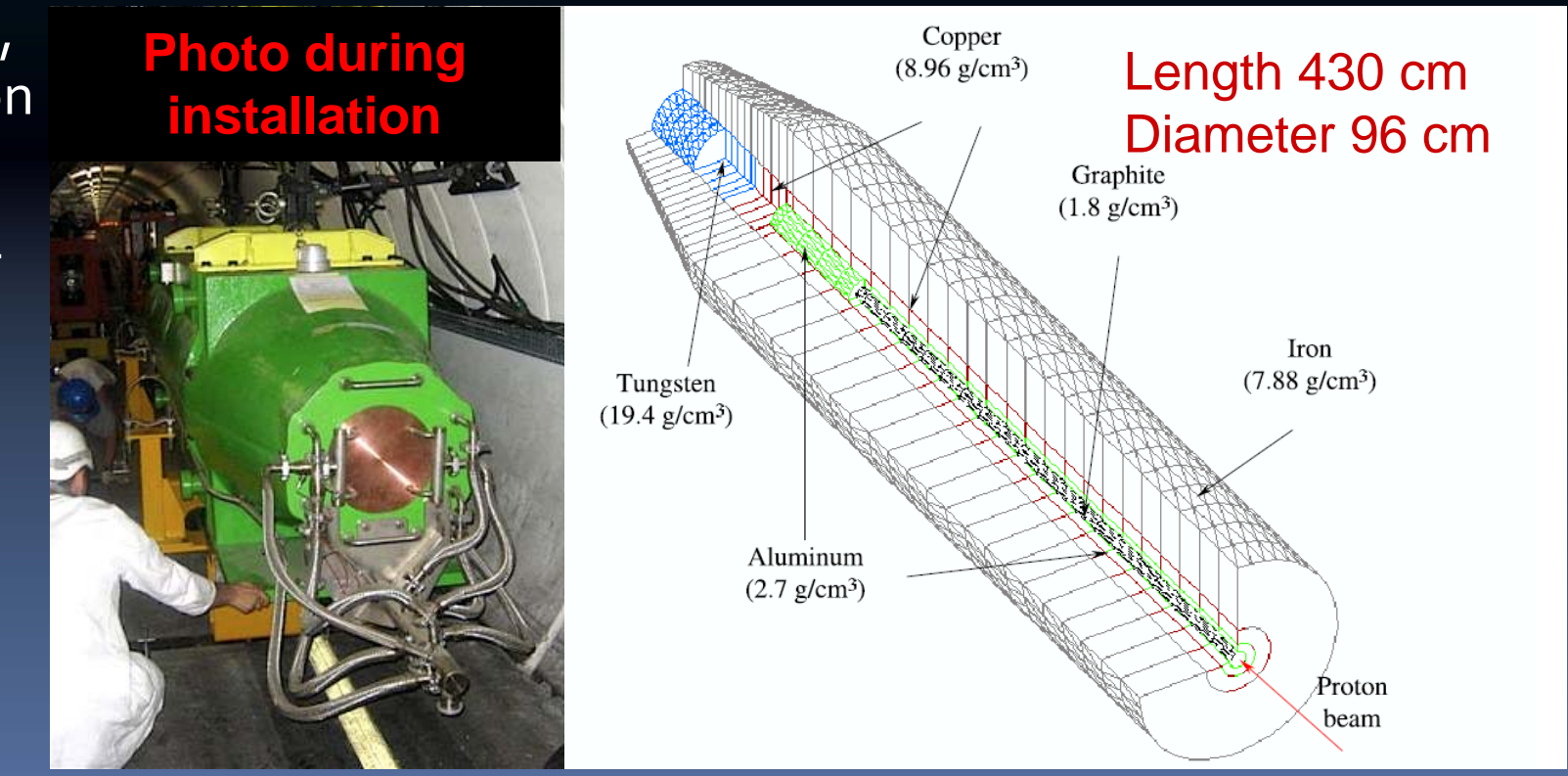




\section{Results on TED data}

- First data taken on Friday $22^{\text {nd }}$ August 2008

- Powered HV channels of 10 modules (5 in each half)

- Data taken on 24 ${ }^{\text {th }}$ August and in September

- Powered all HV channels

About 410 events with about 2000 tracks

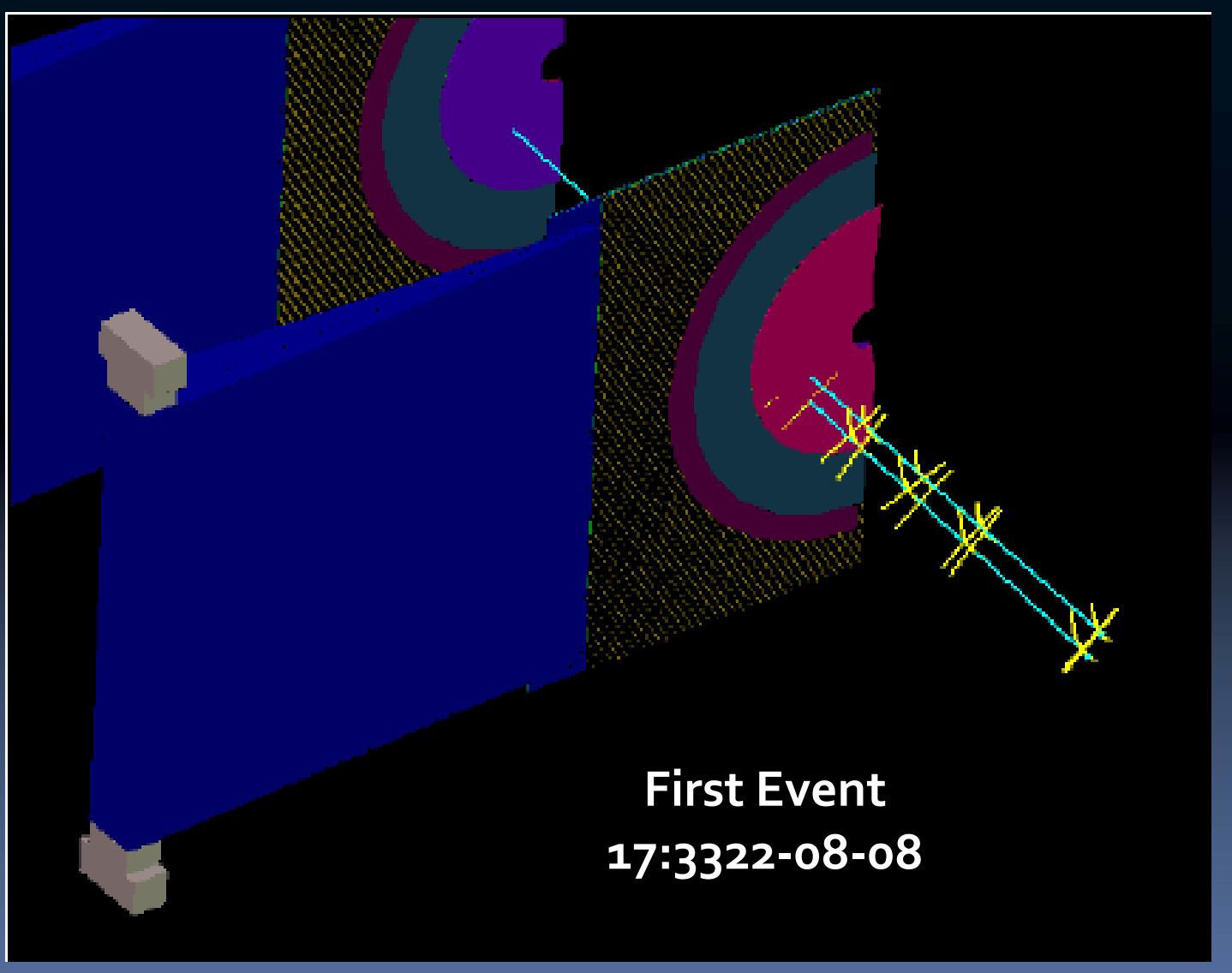

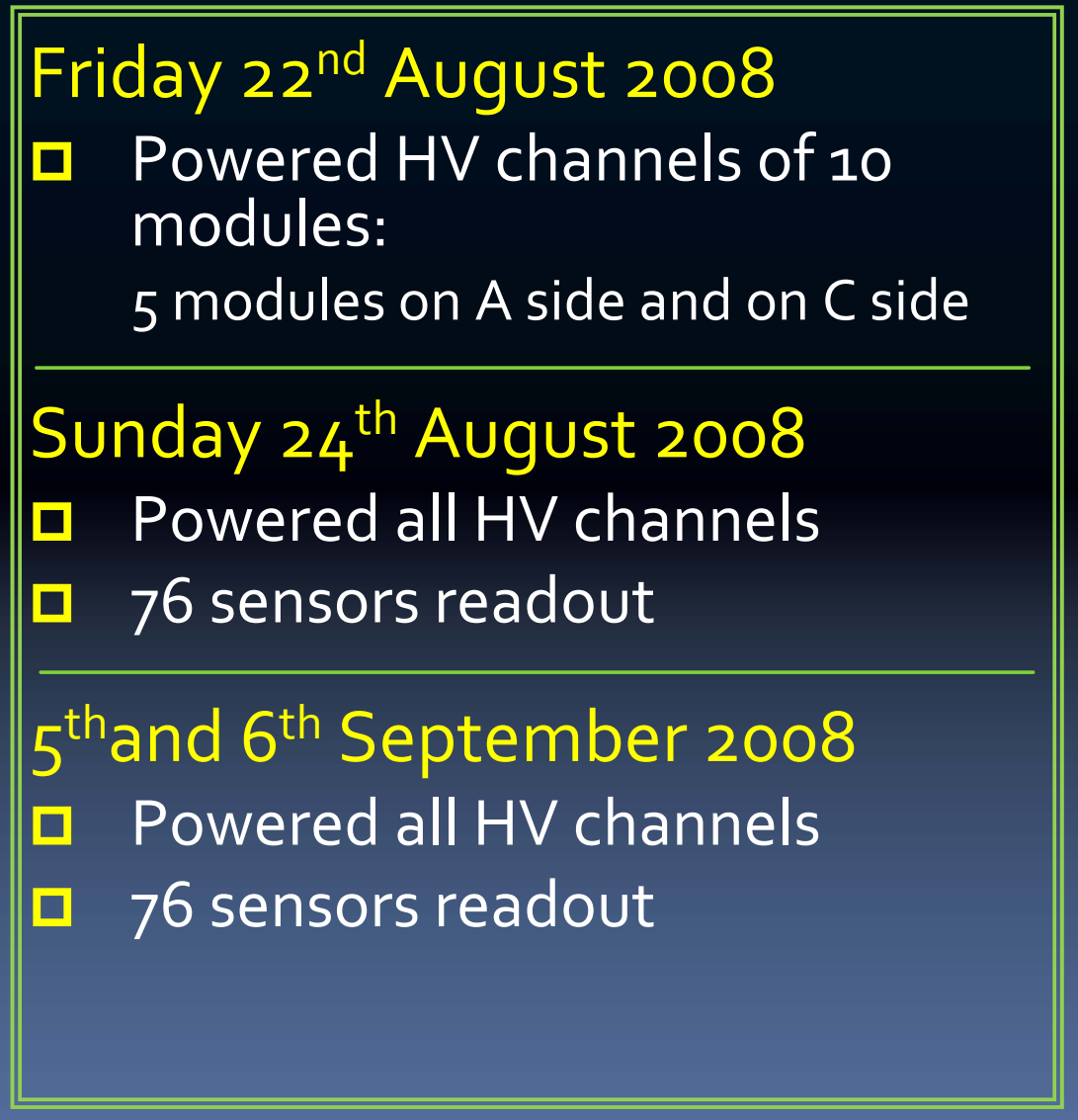




\section{Points distribution}
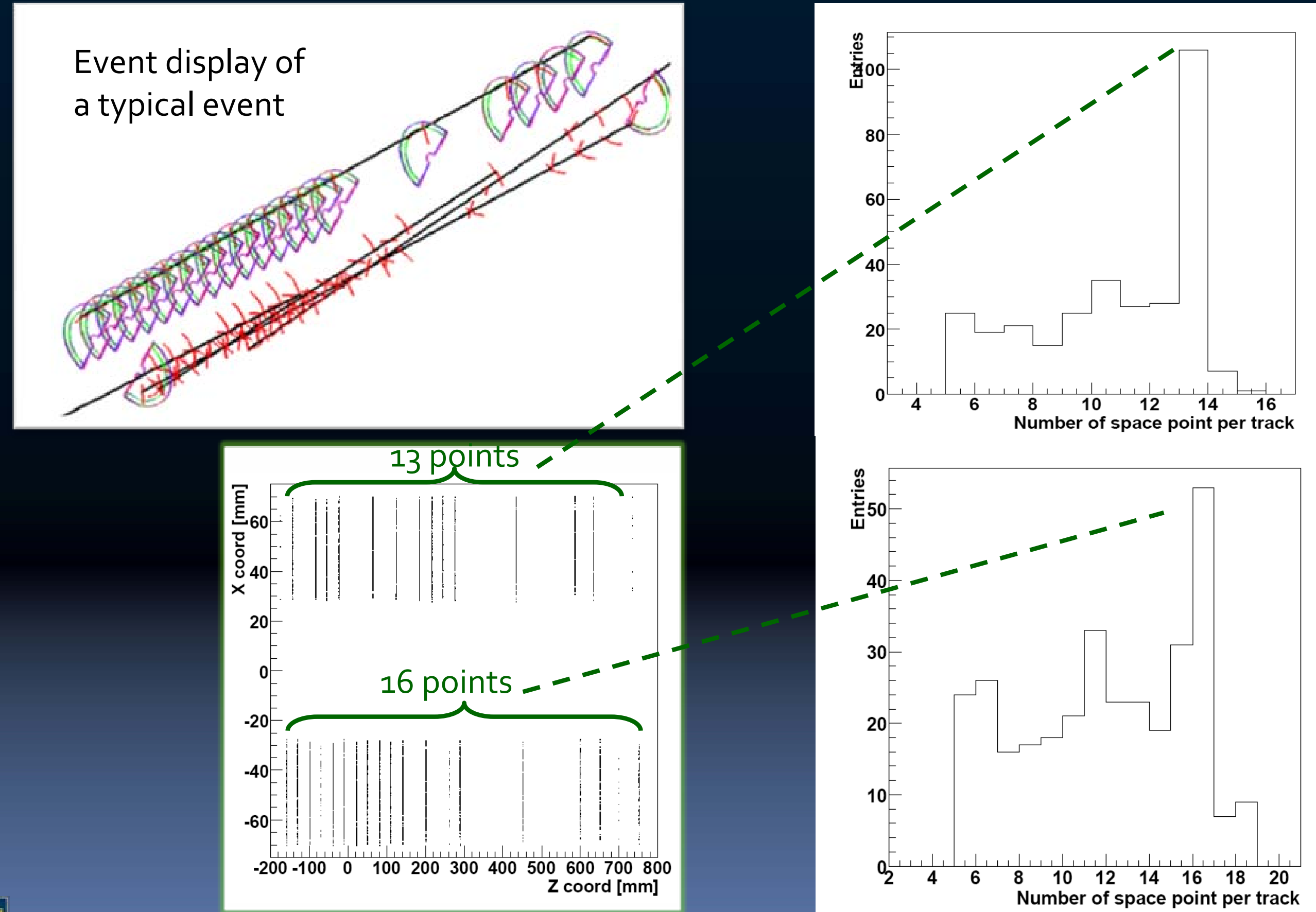


\section{Alignment method}

Alignment of the VELO is following sequence:

1. Module alignment

- Alignment via MILLEPEDE

- Minimisation done with single matrix inversion

2. VELO half alignment

- Alignment via MILLEPEDE

- Minimisation done with single matrix inversion

3. Sensor alignment

- An iterative approach based on residuals
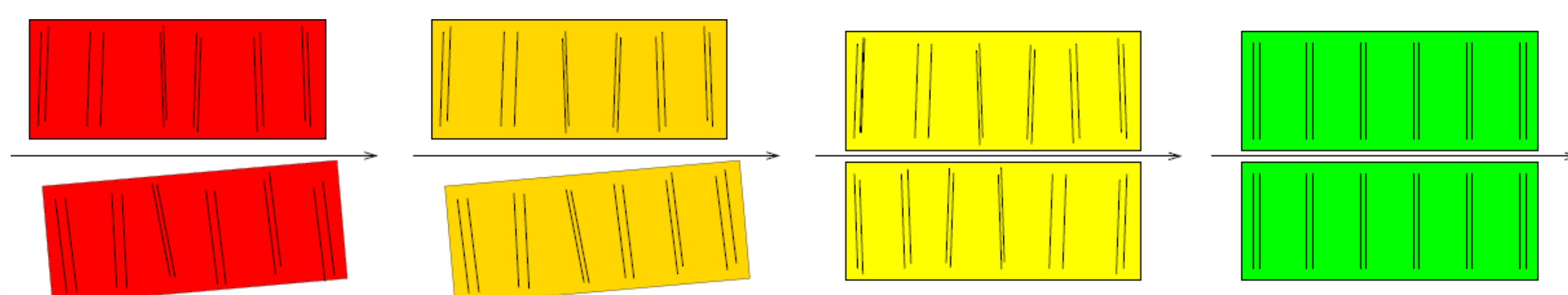


\section{VELO Resolution}

- VELO resolution

- Linear dependency on the pitch

- Dependency on the track angle

- 85\%-90\% clusters are one strip clusters

- Resolution evaluated integrating the results of all sensors
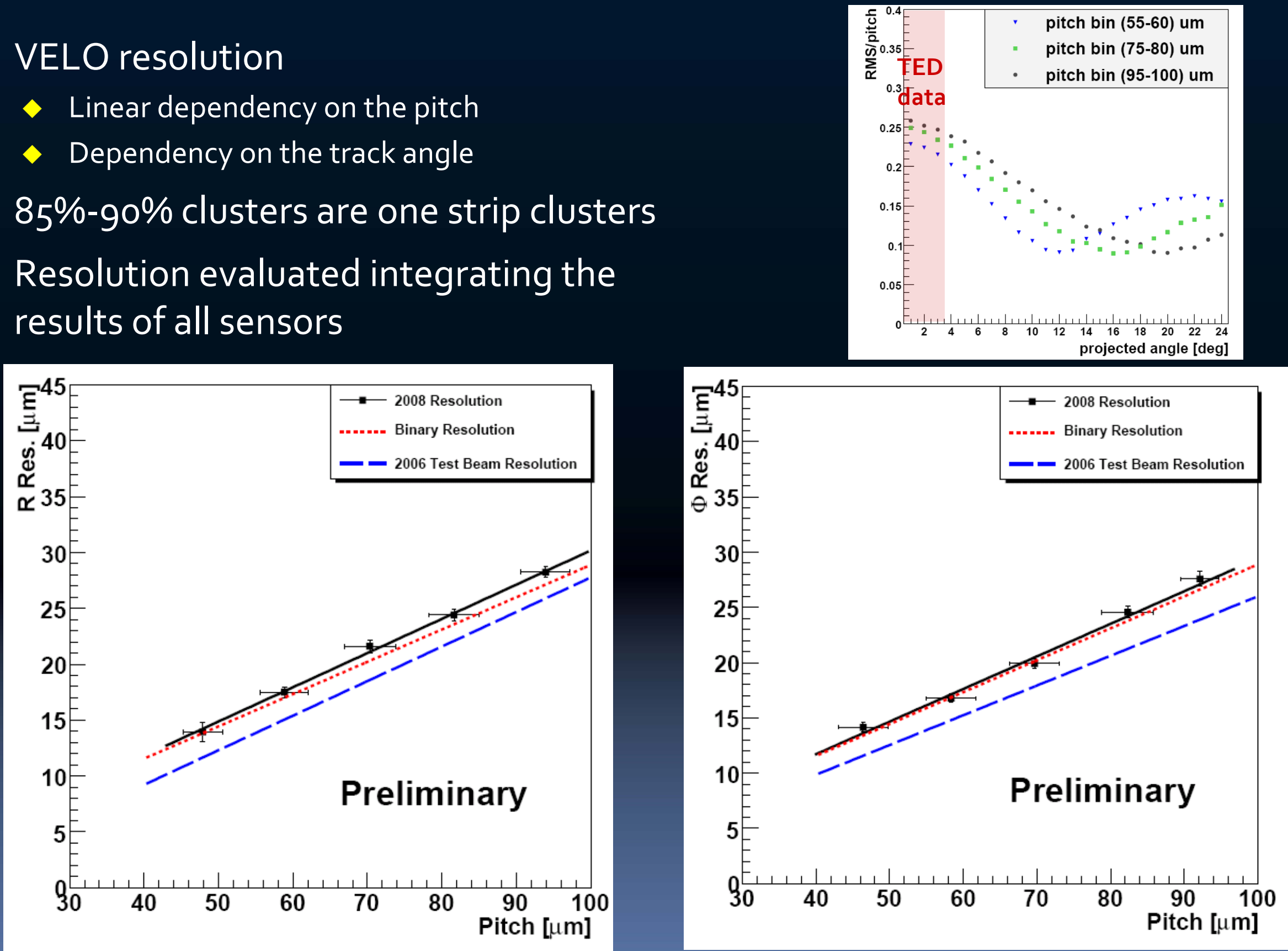


\section{Conclusions}

All components fully installed and tested

- First operation of whole detector under vacuum in June 2008

Full detector operated under vacuum for 18 weeks

99.2\% of channels fully operational

- First ever reconstructed LHC induced tracks in TED events end of August

- These tracks allow the evaluation of the VELO performance improvements foreseen after the proper calibration of DAO boards parameters.

The current module alignment has a precision of $5 \mu \mathrm{m}$ for $X$ and $Y$ translation and $200 \mu \mathrm{rad}$ for $Z$ rotation $\Rightarrow$ micron level precision foreseen with improved resolution

The VELO is ready for the next LHC beam ...

... to contribute to new physics results 